\title{
Neither genotyping nor contact tracing allow correct understanding of multidrug-resistant tuberculosis transmission
}

To the Editor:

The control of tuberculosis (TB) is challenged by the progressive increase of cases of multi-drug-resistant TB (MDR-TB) and extensively drug-resistant TB (XDR-TB). A recent European study underlined the need for data showing how TB control can be improved in terms of case finding, contact tracing, infection control and treatment to prevent further spread of MDR-/XDR-TB in the EU [1].

In France, the number of MDR-TB cases has markedly increased in recent years [2]. This increase represents a challenge for the control of MDR-TB in the city of Paris, in which one-third of all national MDR-TB cases are concentrated [3].

We performed a study to investigate if this increase of MDR-TB index cases is accompanied by increased transmission. The study was conducted between January 1, 2010 and September 30, 2013, and was a prospective collaborative study between the Centre de Lutte Anti-tuberculeuse de Paris (CLAT75) and the Centre National de Référence des Mycobactéries (NRC).

The CLAT75 conducted contact tracing for all patients with MDR-TB and XDR-TB who were either living in Paris themselves or had contacts living in Paris. The NRC performed complete phenotypic and genotypic drug susceptibility testing and genotyping (24-loci mycobacterial interspersed repetitive-unit variable-number tandem repeat (MIRU-VNTR) method) for all MDR-TB and XDR-TB strains.

Of the 68 MDR-TB index cases, only two were born in France. The most frequent country of birth was Georgia, accounting for $37 \%$ of patients (25/68). The delay between arrival in France and diagnosis of TB was less than 1 year for $59 \%$ of cases (40/68). The vast majority of patients had pulmonary TB $(97 \%, 66 / 68)$, and $69 \%$ were smear-positive. Of the 66 TB strains tested for second-line drug susceptibility, 17 were XDR.

Of the 68 index MDR-TB cases, 36 had no identified contacts in France, while the remaining 32 MDR-TB index cases had a total of 84 contacts (1-15 contacts for each index case). About half of the contacts were born in the same country as the index case, while a quarter of contacts were born in a different country and the remaining quarter were born in France.

Of the 84 contacts, 21 (25\%) were living in the same house as the index case, 21 (25\%) had contacts through collective accommodation, 17 (20\%) were friends or family, and $25(30 \%)$ were professional contacts. As a whole, contact between index case and contact case was considered as close ( $>100 \mathrm{~h}$ contact and/or living in the same house) for $22 / 84(26 \%)$ of contacts.

Of the 84 contacts, 52 (62\%) were not infected, 23 (27\%) had latent TB infection (LTBI), three (4\%) had MDR-TB, two (2\%) had drug-susceptible TB unrelated to that of the index case and four (5\%) had healed TB.

When compared with the index case, the three patients with secondary MDR-TB were found to share the same MIRU-VNTR, had the same drug-resistance profile (patients 1-2, 3-4 and 5-6 in table 1), were born in the same country and were classified as close contacts.

@ERSpublications

Even combined contact tracing and genotyping fail to explain how MDR-TB transmission occurs in one third of cases http://ow.ly/2ZKB30dRVGw

Cite this article as: Fournier A, Bernard C, Sougakoff W, et al. Neither genotyping nor contact tracing allow correct understanding of multidrug-resistant tuberculosis transmission. Eur Respir J 2017; 50: 1700891 [https://doi.org/10.1183/13993003.00891-2017]. 


\begin{tabular}{|c|c|c|c|c|c|c|c|c|c|c|c|c|}
\hline \multirow[t]{2}{*}{ Patient number } & \multirow[t]{2}{*}{ Identification method } & \multirow[t]{2}{*}{ Country of birth } & \multirow[t]{2}{*}{ Disease type } & \multicolumn{8}{|c|}{ Genotyping } & \multirow[t]{2}{*}{ MIRU-VNTR } \\
\hline & & & & katG315 & $\operatorname{inh} A$ & $r p o B$ & gyrA & gyrB & pnca & rrs & $e m b B$ & \\
\hline 1 & Contact tracing" & Georgia & Pulmonary & S315T & $\mathrm{S}$ & S531L & $\mathrm{D} 94 \mathrm{H}$ & $\mathrm{S}$ & $\mathrm{S}$ & $\mathrm{S}$ & M306V & $\begin{array}{l}244223352644 \\
425173353623\end{array}$ \\
\hline 2 & Contact tracing & Georgia & Pulmonary and genital & S315T & $\mathrm{S}$ & S531L & $\mathrm{D94H}$ & $\mathrm{S}$ & $\mathrm{S}$ & $\mathrm{S}$ & M306V & $\begin{array}{r}244223352644 \\
425173353623\end{array}$ \\
\hline 3 & Contact tracing & Algeria & Pulmonary & S315T & $-15 c>t$ & $\mathrm{H} 526 \mathrm{D}$ & $\mathrm{S}$ & E540V & T100P & $\mathrm{S}$ & M306I & $\begin{array}{r}223234242434 \\
425143323732\end{array}$ \\
\hline 4 & Contact tracing & Algeria & Pulmonary & S315T & $-15 c>t$ & $\mathrm{H} 526 \mathrm{D}$ & $\mathrm{S}$ & E540V & $\mathrm{T} 100 \mathrm{P}$ & $\mathrm{S}$ & M306I & $\begin{array}{r}223234242434 \\
425143323732\end{array}$ \\
\hline 5 & Contact tracing & Algeria & Pulmonary & S315T & $\mathrm{S}$ & S531L & $\mathrm{S}$ & $\mathrm{S}$ & V139M & $\mathrm{S}$ & M306V & $\begin{array}{l}334323312244 \\
225153333622\end{array}$ \\
\hline 6 & Contact tracing & Algeria & Pulmonary & S315T & $\mathrm{S}$ & $\mathrm{S} 531 \mathrm{~L}$ & $\mathrm{~S}$ & $\mathrm{~S}$ & V139M & $\mathrm{S}$ & M306V & $\begin{array}{l}334323312244 \\
225153333622\end{array}$ \\
\hline 7 & Genotyping & Sudan & Pulmonary & S315T & $\mathrm{S}$ & S531L & $\mathrm{S}$ & $\mathrm{S}$ & V139M & $\mathrm{S}$ & M306V & $\begin{array}{r}334323312244 \\
225153333622\end{array}$ \\
\hline 8 & Genotyping & China & Pleural & S315T & $\mathrm{S}$ & S531L & $\mathrm{S}$ & $\mathrm{S}$ & G97D & $S$ & S & $\begin{array}{r}222213222234 \\
225153333622\end{array}$ \\
\hline 9 & Genotyping & Romania & Pulmonary & S315T & $\mathrm{S}$ & S531L & $\mathrm{S}$ & $\mathrm{S}$ & G97D & $\mathrm{S}$ & $\mathrm{S}$ & $\begin{array}{r}222213222234 \\
225153333622\end{array}$ \\
\hline 10 & Genotyping & Romania & Pleural & S315T & $-15 c>t$ & S531L & $\mathrm{S}$ & $\mathrm{S}$ & $\mathrm{S}$ & $S$ & S & $\begin{array}{r}235237232244 \\
425113323632\end{array}$ \\
\hline 11 & Genotyping & Ukraine & Pulmonary & S315T & $-15 c>t$ & S531L & $\mathrm{S}$ & $\mathrm{S}$ & $\mathrm{S}$ & $\mathrm{S}$ & $\mathrm{S}$ & $\begin{array}{r}235237232244 \\
425113323632\end{array}$ \\
\hline
\end{tabular}


Regarding the two contact cases who developed susceptible TB not related to the MDR-TB index case, one was born in France and was living in shelters for the homeless, while the other was born outside France and had a non-close contact with the index MDR-TB case in a professional setting.

MIRU-VNTR and resistance genotype analysis of MDR-TB strains identified three other possible transmissions (table 1). These corresponded to two new pairs (patients 8-9 and 10-11) and to a third case linked to a previously identified cluster (patient 7 linked to patients 5 and 6). Retrospective investigation did not allow precise identification of the circumstances of transmission, but showed that patients 10 and 11 lived and worked in close proximity.

Compared with patients with drug-susceptible TB in Paris, the average number of contacts per index case was lower for MDR-TB cases: 1.2 versus $4.2(\mathrm{p}<0.05)$ [4]. This may be explained by the fact that these MDR-TB cases had only recently arrived in France and thus had not had time to make many contacts. Despite this low number of contacts, we identified six secondary cases (9\%). This proportion is higher than that for drug-susceptible TB in Paris (0.6\%) but close to what has been described in Amsterdam (9.5\%) and in a previous meta-analysis (8\%) [5-7]. Of these, three co-prevalent cases were identified by contact tracing by CLAT75 and corresponded to close contacts. For these cases, the transmission possibly occurred outside France, as they all came from the same country and were close relatives of the index case. The other three secondary cases identified by genotyping were considered occasional contacts because the retrospective investigation failed to identify any link with the index case; all contacts were born in a different country from the index case and none was born in France. During this study period, no secondary MDR-TB case occurred in patients born in France, in contrast with the case that occurred afterwards, which had already been reported [3].

In this study, we used two methods to identify transmission: contact tracing and genotyping. Contact tracing identified five cases of TB, of which only three were confirmed as linked to index MDR-TB case by genotyping. Thus, $40 \%$ of presumed secondary MDR cases were due to susceptible strains. This is much higher than the proportion (10\%) reported from Peru [8], but in line with data from Hong Kong (60\%) and Canada (100\%) [9, 10]. This difference is probably explained by the local epidemiology and the prevalence of MDR-TB. Practically, these data should be known when deciding to provide treatment for LTBI. It has been suggested that fluoroquinolones are cost-effective for the treatment of MDR LTBI [11], but this strategy will probably need to be adapted to 1) the actual incidence of MDR-TB cases among contacts of MDR-TB index cases in each particular epidemiological setting (60\% in this study) and 2) the proportion of fluoroquinolone-susceptible strains in the index case population (only 59\% in this study).

A second important finding of this study was that there was a low identification rate with contact tracing; of six secondary cases, only three (50\%) were identified by contact tracing. According to a recent study in the UK, 95\% of MDR-TB transmission was missed by contact tracing [12]. Although this percentage can vary from one setting to another, these missed cases underline the importance of genotyping when trying to measure the risk of transmission of MDR-TB [13]. However, it must also be emphasised that despite the identification of transmission by genotyping in our study, the retrospective contact tracing was not able to identify the contact that began this transmission. There are different explanations for this lack of identification: 1) by definition, genotyping is performed when a secondary case occurs, and the later it occurs, the more difficult the retrospective contact investigation; and 2) these patients with MDR-TB were difficult to contact, as they were often homeless, did not speak French and were not willing to cooperate because of their illegal situation. As consequence, there was no further identification of new unknown contact cases and no complementary investigation. Thus, this retrospective analysis did not allow implementation of preventive measures in a population that would have been missed by the primary contact investigation performed by CLAT75. Finally, genotyping gave an exhaustive image of transmission but did not explain how transmission occurred.

In conclusion, this study underlines the difficulties of conducting contact investigation among patients with MDR-TB in France. Genotyping is an important tool, but does not replace information gathered by contact investigation.

Arthur Fournier $^{1}$, Christine Bernard ${ }^{2,3,4}$, Wladimir Sougakoff ${ }^{2,3,4}$, Sylvie Quelet ${ }^{1}$, Fadi Antoun ${ }^{1}$, Cécile Charlois$\mathrm{Ou}^{1}$, Isabelle Dormant ${ }^{1}$, Marie-Odile Dufour ${ }^{1}$, Nora Hocine ${ }^{1}$, Vincent Jarlier ${ }^{2,3,4}$ and Nicolas Veziris ${ }^{2,3,4}$

${ }^{1}$ Centre de Lutte Anti-Tuberculeuse de Paris (CLAT75), Sous-direction de la Santé, DASES, Département de Paris, Paris, France. ${ }^{2}$ Sorbonne Universités, UPMC Univ Paris 06, CR7, Centre d'Immunologie et des Maladies Infectieuses, CIMI, team E13 (Bacteriology), Paris, France. ${ }^{3}$ INSERM, U1135, Centre d'Immunologie et des Maladies Infectieuses, CIMI, team E13 (Bacteriology), Paris, France. ${ }^{4}$ AP-HP, Hôpital Pitié-Salpêtrière, Centre National de Référence des Mycobactéries et de la Résistance des Mycobactéries aux Antituberculeux, Bactériologie-Hygiène, Paris, France.

Correspondence: Nicolas Veziris, CIMI-Paris U1135, E13, 91, Boulevard de l'hôpital, 75013 Paris, France.

E-mail: nicolas.veziris@upmc.fr 
Received: March 272017 | Accepted after revision: June 092017

Support statement: CNR MyRMA is supported by an annual grant from Santé Publique France. Funding information for this article has been deposited with the Crossref Funder Registry.

Conflict of interest: Disclosures can be found alongside this article at erj.ersjournals.com

Acknowledgements: Author contributions: N. Veziris is the guarantor of the paper. A. Fournier, F. Antoun and N. Veziris designed the study, gathered data and wrote the manuscript. C. Bernard, W. Sougakoff and C. Charlois-Ou gathered data and corrected the manuscript. S. Quelet and V. Jarlier corrected the manuscript. I. Dormant, M-O. Dufour and N. Hocine gathered data.

\section{References}

1 De Beer JL, Kodmon C, van der Werf MJ, et al. Molecular surveillance of multi- and extensively drug-resistant tuberculosis transmission in the European Union from 2003 to 2011. Euro Surveill 2014; 19: article 2.

2 Bernard C, Brossier F, Sougakoff W, et al. A surge of MDR and XDR tuberculosis in France among patients born in the Former Soviet Union. Euro Surveill 2013; 18: 20555.

3 Lafeuille E, Veziris N, Sougakoff W, et al. XDR-tuberculosis in France: Community transmission due to non-compliance with isolation precautions. Med Mal Infect 2016; 46: 52-55.

4 Fournier A, Antoun F, Collignon A, et al. [Screening contacts for latent tuberculosis infection (LTBI) using an interferon test in Paris in 2009]. Rev Mal Respir 2012; 29: 28-39.

5 Fournier A, Antoun F, Charlois Ou C, et al. [Longitudinal follow-up of contact subjects of cases of tuberculosis in Paris]. Rev Mal Respir 2015; 32: 705-714.

6 Sloot R, Schim van der Loeff MF, Kouw PM, et al. Risk of tuberculosis after recent exposure. A 10-year follow-up study of contacts in Amsterdam. Am J Respir Crit Care Med 2014; 190: 1044-1052.

7 Shah NS, Yuen CM, Heo M, et al. Yield of contact investigations in households of patients with drug-resistant tuberculosis: systematic review and meta-analysis. Clin Infect Dis 2014; 58: 381-391.

8 Becerra MC, Appleton SC, Franke MF, et al. Tuberculosis burden in households of patients with multidrug-resistant and extensively drug-resistant tuberculosis: a retrospective cohort study. Lancet Lond Engl 2011; 377: 147-152.

9 Leung ECC, Leung CC, Kam KM, et al. Transmission of multidrug-resistant and extensively drug-resistant tuberculosis in a metropolitan city. Eur Respir J 2013; 41: 901-908.

10 Johnston J, Admon A, Ibrahim A, et al. Long term follow-up of drug resistant and drug susceptible tuberculosis contacts in a Low incidence setting. BMC Infect Dis 2012; 12: 266.

11 Fox GJ, Oxlade O, Menzies D. Fluoroquinolone therapy for the prevention of multidrug-resistant tuberculosis in contacts. a cost-effectiveness analysis. Am J Respir Crit Care Med 2015; 192: 229-237.

12 Anderson LF, Tamne S, Brown T, et al. Transmission of multidrug-resistant tuberculosis in the UK: a cross-sectional molecular and epidemiological study of clustering and contact tracing. Lancet Infect Dis 2014; 14: 406-415.

13 Attamna A, Chemtob D, Attamna S, et al. Risk of tuberculosis in close contacts of patients with multidrug resistant tuberculosis: a nationwide cohort. Thorax 2009; 64: 271. 